$$
\begin{aligned}
& \text { DOE/ER/14053--T3 } \\
& \text { DE.93 } 00.5250
\end{aligned}
$$

\title{
COMBUSTION-RELATED STUDIES USING WEAKLY-BONDED COMPLEXES
}

Submitted to : U. S. Department of Energy

Division of Basic Energy Sciences

Germantown, R. L.

Germantown, MD 20767

Attention: Dr. Allan Laufer

(301) 353-5820

Submitted by: Department of Chemistry

University of Southern California

Los Angeles, CA 90089-0482

Attention: Contracts and Grants Department (213) $740-7762$

Principal Investigator:
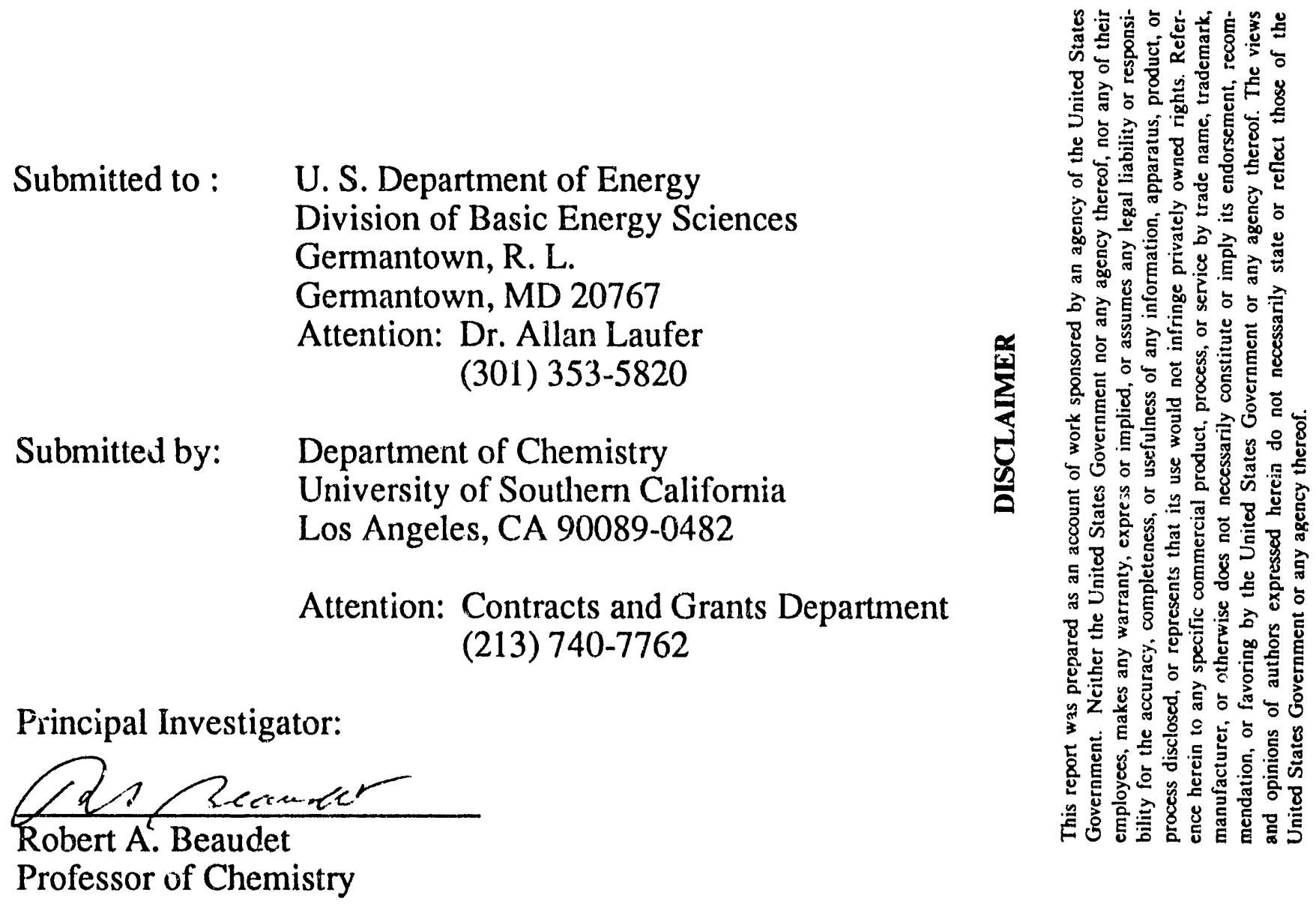

(213) $740-4125$

MHSIER 
April 20, 1991

\title{
PROGRESS REPORT
}

\section{COMBUSTION-RELATED STUDIES USING WEAKLY-BONDED COMPLEXES}

\author{
Robert A. Beaudet
}

\author{
Department of Chemistry \\ University of Southern California \\ Los Angeles, CA 90089-0482
}

Tel: (213) 740-4125

FAX: (213) 746-4945

\section{PROGRAM SCOPE.}

Combustion remains one of the most widely used and studied of all chemical processes. At the macroscopic level, research is concerned with understanding and modeling flame temperatures, flame speeds, detonation limits, atid similar characteristics, while at the microscopic level, reaction mechanisms and kinetic processes of individual species are examined in detail. This work is concerned specifically with microscopic-level phenomena of importance in combustion. However, instead of using homogeneous gaseous samples, as we have done in the past, weakly bonded adducts formed in supersonic expansions are investigated spectroscopically and used to limit the angles and impact parameters of bimolecular encounters. Also, we examine species in which a free radical such as atomic oxygen is bonded to a stable molecule in a shallow well outside the reaction barrier. These species can be used for several studies such as those involving photoinitiated reactions. The main experimental approach uses tunable diode laser (TDL) IR absorption spectroscopy to monitor and characterize in detail the complexes of interest, and laser photoinitiation and LIF/MPI detection to examine bimolecular processes in which the adducts are used as precursors.

In the first phase, geometries and other molecular properties are being determined from vibration-rotational spectra. In the second phase, these complexes will be used as precursors to study photoinitiated reactions in precursor geometry limited environments. 
Two complementary classes of binary complexes are being investigated. The first involves molecular oxygen and hydrogen containing constituents (e.g. $\mathrm{O}_{2}-\mathrm{HCN}, \mathrm{O}_{2}-\mathrm{HF}$, $\mathrm{O}_{2}-\mathrm{HCl}, \mathrm{O}_{2}-\mathrm{HBr}, \mathrm{O}_{2}-\mathrm{HI}$ and $\mathrm{O}_{2}$-hydrocarbons). These species are interesting candidates for study since upon photodissociating the hydride portion, the reaction of $\mathrm{H}$ and $\mathrm{O}_{2}$ via the vibrationally excited $\mathrm{HO}_{2} \dagger$ intermediate can conceivably be studied, \{e.g. $\left.\mathrm{BrH}-\mathrm{O}_{2}+\mathrm{hv}(193 \mathrm{~nm}) \rightarrow \mathrm{Br}-\mathrm{H}-\mathrm{O}_{2} \rightarrow \mathrm{Br}+\mathrm{HO}_{2}^{\dagger} \rightarrow \mathrm{Br}+\mathrm{OH}+\mathrm{O}\right\}$. High resolution IR spectroscopy of such complexes has not been obtained previously and the structural $\mathrm{i}_{\mathrm{i}}$ formation deriving from IR spectra is certainly very useful for better designing and understanding photoinitiated reactions that occur in these complexes.

The second thrust area involves the study of a set of novel species involving oxygen atoms and small molecules such as $\mathrm{HF}, \mathrm{HCl}, \mathrm{HBr}, \mathrm{HI}, \mathrm{HCN}$ and simple hydrocarbons. An expansion gas will be seeded with a precursor such as $\mathrm{NO}_{2}$ or $\mathrm{SO}_{2}$ and a second constituent. $\mathrm{O}\left({ }^{3} \mathrm{P}\right)$ will be prepared by precursor photolysis just before the start of supersonic expansion. Since the reactions of $\mathrm{O}\left({ }^{3} \mathrm{P}\right)$ and the above mentioned small molecules have significant activation energies, the complexes will be able to form and survive in the free-jet expansions, e.g., the $\mathrm{O}\left({ }^{3} \mathrm{P}\right)+\mathrm{HCl}$ reaction has an activation energy of $22 \mathrm{~kJ} / \mathrm{mol}$., which is considerably higher than the thermal collisional energy. Hence, the complex can be stabilized in the shallow van der Waals potential well just outside the activation barrier. Our initial objective is to study structural properties of these clusters by using laser IR spectroscopy. Once that proves successful, we will exploit vibrational excitation of the HX to promote the hydrogen exchange reaction of $\mathrm{O}+$ $\mathrm{HX} \rightarrow \mathrm{OH}+\mathrm{X}$ occurring in these complexes. The nascent state distribution of the $\mathrm{OH}$ product can be probed with LIF. Experiments are also under way in which the nascent product state distribution of a photodissociation can be probed by using IR spectroscopy.

\section{MILESTONES.} project:

To achieve these goals, we have set out to achieve the following milestones in this

1. Construct a vacuum system compatible with the use of a large pulsed slit valve for the required sensitivity.

2. Design and construct an expansion-cooled radical source intense enough to enable IR detection of these species. 
3. Obtain optimum conditions for generation of high concentrations of $\mathrm{O}\left({ }^{3} \mathrm{P}\right)$.

4. Prepare van der Waals complexes consisting of $O\left({ }^{3} \mathrm{P}\right)$ in the free jet expansion and obtain IR TDL spectra of these species to determine their structural properties.

5. Photodissociate the $\mathrm{O}\left({ }^{3} \mathrm{P}\right)$ containing clusters to study the photoinitiated reactions occurring in these novel species.

6. Prepare van der Waals complexes of molecular oxygen with small molecules of interest such as $\mathrm{HCN}, \mathrm{N}_{2} \mathrm{O}, \mathrm{HX}$, etc.

7. Validate the reliability of determining van der Waals complex structures from standard spectroscopic methods.

\section{EXPERIMENTAL.}

\section{A. Pulsed slit expansions.}

We have now constructed two pulsed slit expansion systems. The first was built four years ago and has a $40 \times 0.1 \mathrm{~mm}$ pulsed slit nozzle. ${ }^{1}$ However, as we proceeded with this work, it became clear that we needed more sensitivity. This could best be achieved by using a larger pumping system and a longer slit nozzle. The newer system built during the last two and a half years has a much faster pumping system that sustains a $120 \times 0.2 \mathrm{~mm}$ pulsed slit with stagnation pressures of $5 \mathrm{~atm}$. In fact, it was designed to sustain a $25 \mathrm{~cm}$ slit! Being pulsed, the duty cycle is reduced to $\sim 0.1 \%$ of that for the equivalent continuous expansion, so a high molecular flux can be maintained with low background pressure. With the nozzle open for $\sim 1 \mathrm{~ms}$ at $10 \mathrm{~Hz}$, the background pressure is below $10^{-4}$ Torr in both systems when argon is used.

Long slits also provide reasonable optical paths for absorption spectroscopy and reduce Doppler linewidths considerably. With the small slit, we have obtained IR absorptions of $10 \%$ with $\mathrm{Ar}-\mathrm{CO}_{2}$. The valves that we presently use are simple modified General Valves energized by solenoids; a diagram is shown in Fig. 1 for the small slit. The larger slit is similar, but it is driven by three selenoids. A linear plug makes the seal. We find this design more reliable than piezoelectric driven valves. ${ }^{2}$ The large system can pump helium quite efficiently up to stagnation pressures of $2 \mathrm{~atm}$. This was essential for 
obtaining molecular oxygen binary clusters. Expansion cooling is controlled by varying the backing pressure and the carrier gas composition. The large system was constructed during the first 18 months of this grant. The $\mathrm{O}_{2}-\mathrm{N}_{2} \mathrm{O}$ cluster and the photolysis of $\mathrm{SO}_{2}$ could not have succeeded without the new larger apparatus. In both cases, helium had to be used for the carrier gas and the longer path lengths were also essential.

\section{PULSED SLOTTED NOZZLE}

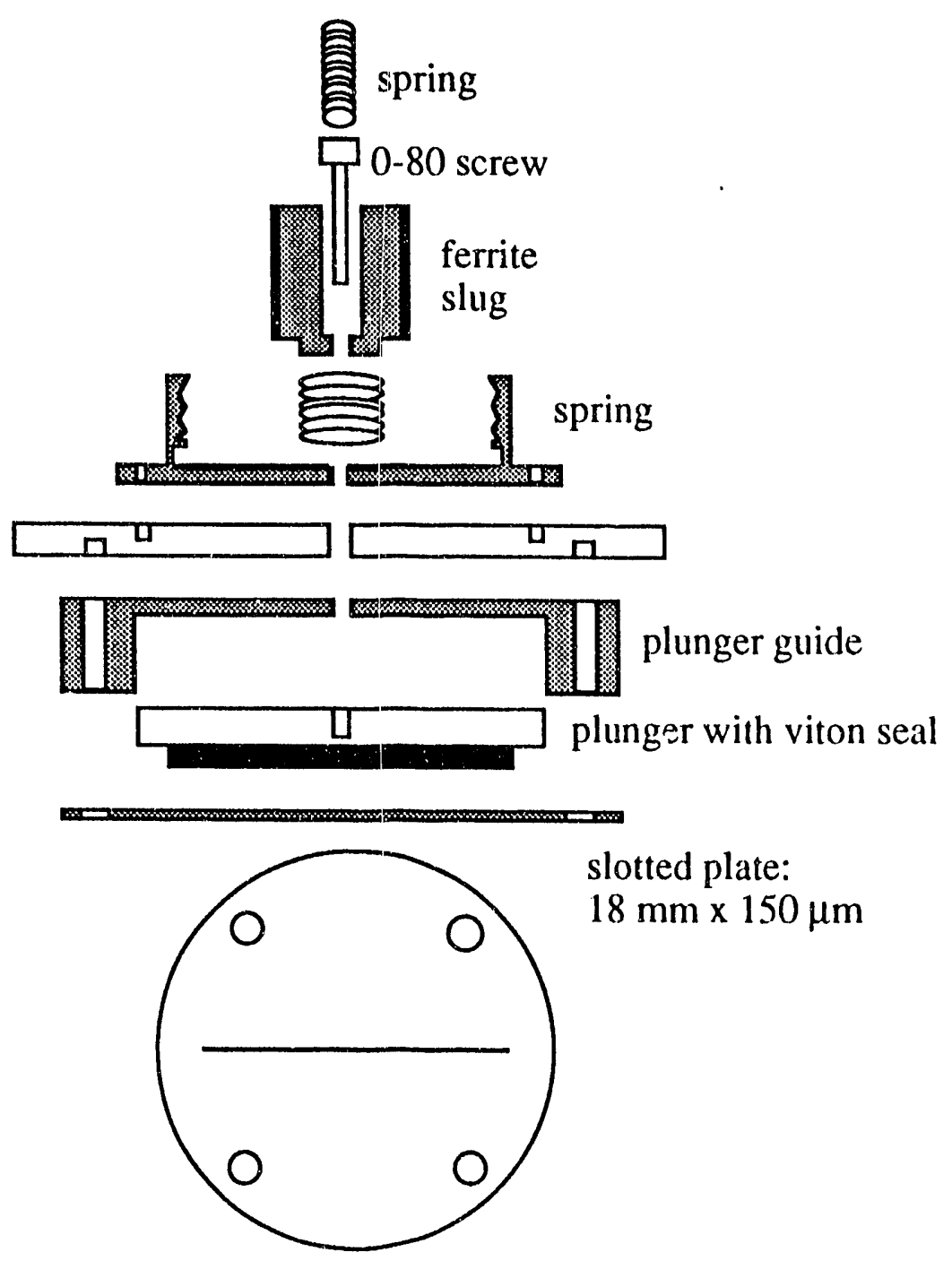

Fig. 1 Cross-sectional schematic drawing of the small pulsed slit nozzle.

The main chambers for both systems are electropolished rectangular boxes $(50 \mathrm{x}$ $50 \times 35 \mathrm{~cm}^{3}$ for the smaller system) made from $2 \mathrm{~cm}$ thick stainless steel, with $25 \mathrm{~cm}$ dia. 
ports on 5 sides. The smaller system is pumped by a Varian VHS-10 diffusion pump with a nominal speed of $55001 \mathrm{~s}^{-1}$, reduced to $2200 \mathrm{l} \mathrm{s}^{-1}$ by a gate valve and $\mathrm{LN}_{2}$ trap; the throughput is 7.7 Torr $1 \mathrm{~s}^{-1}$. A small part of the expansion passes through a $0.5 \mathrm{~mm}$ skimmer into a differentially pumped chamber, followed by another skimmer and the mass spectrometer chamber maintained at $10^{-8}$ Torr. Thus, we can continuously monitor the composition, time dependence and shape of the gas pulse with the quadrupole mass spectrometer. This feature is very helpful for optimizing complex formation. IR windows for passing the TDL output are installed on the two ports perpendicular to the expansion axis. The top port is unused and available for photoexcitation or double resonance irradiation.

The large system has a slightly larger chamber pumped by a vapor booster pump (Edward model 18B4A) which is backed by a Leybold Roots blower/mechanical pump combination. The booster pump has a pumping speed of $4000 \mathrm{l} / \mathrm{s}$ with high throughput even at high pressures. The chamber is connected to the pump by a large 12 "diameter stainless steel U-shaped tube connected to the top of the chamber. This tube with the chamber also serves as a dump volume when the pulsed valve is opened. The system is illustrated in Fig.2.

\section{LARGE VACUUM SYSTEM}

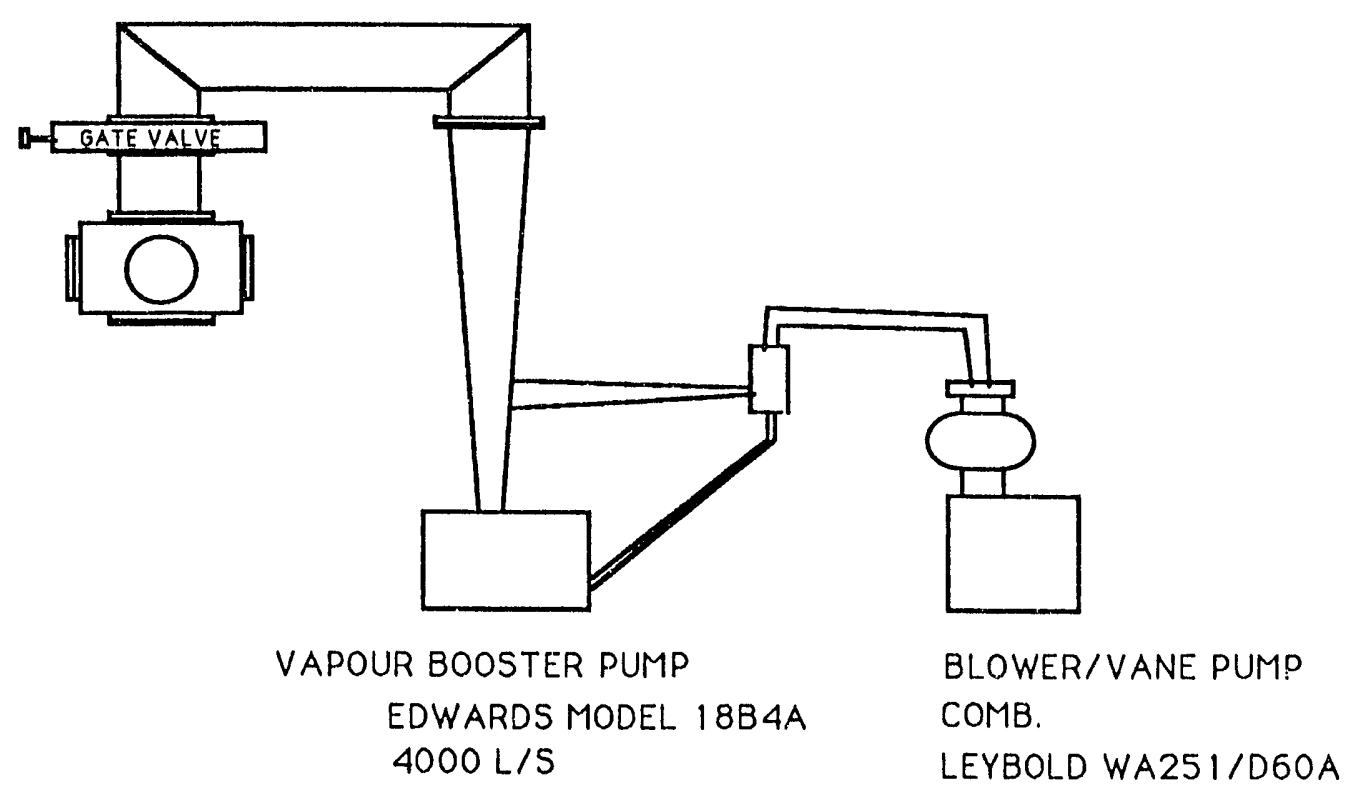

Fig. 2. Schematic of large vacuum system. 


\section{B. Pulsed radical sources.}

Various methods have alrtady been reported for producing free radicals and atomic species in supersonic jets. These include:

1. Photolysis of a precursor molecule after the orifice, during expansion. The distance from the orifice can be varied to optimize radical production. ${ }^{2}$

2. Photolysis prior to expansion in the nozzle chamber. This requires injecting the second reagent just behind the nozzle. ${ }^{3}$

3. An electrical discharge between an electrode and the orifice face of the source. ${ }^{4}$ The discharge can be either inside the nozzle or in the large chamber after the expansion.

The first technique is the most selective, since light of the correct frequency can photolyze one species. When irradiation is done close to the orifice, fragments can complex in the collisional region close to the nozzle. The effluent is then cooled by expansion. Method (3) can produce high concentrations of radicals, but is not always selective or easily controlled. Thus, there are many different species present in the beam. Also it is not easily adapted to a pulsed valve. It is also important to produce kinetically cold atoms so they do not react or escape from the expansion.

We have constructed a pulsed slit valve that produces intermediates and transients effectively by laser photolysis. A secondary chamber constructed from quartz plates lies over the pulsed nozzle and provides a secondary expansion. This chamber and the slit are formed by two UV transmitting quartz plates. The length of the slit $(38 \mathrm{~mm} \mathrm{x}$ $0.15 \mathrm{~mm}$ ) has been selected to match the size of the excimer laser beam. The laser is focused with a cyl:ndrical lens into the gas just before it exits the second slit. The highest yield is obtained when the photolysis laser is focussed about one millimeter upstream from the slit opening. In this way, the radicals formed have some drift time to thermalize before being further cooled by the supersonic expansion. Surprisingly, the quartz plates do not become fouled and opaque. Fig. 3 illustrates the experimental set-up. We can also achieve satisfactory photolysis by directing the laser beam head-on into a regular slit nozzle along the translational axis. 


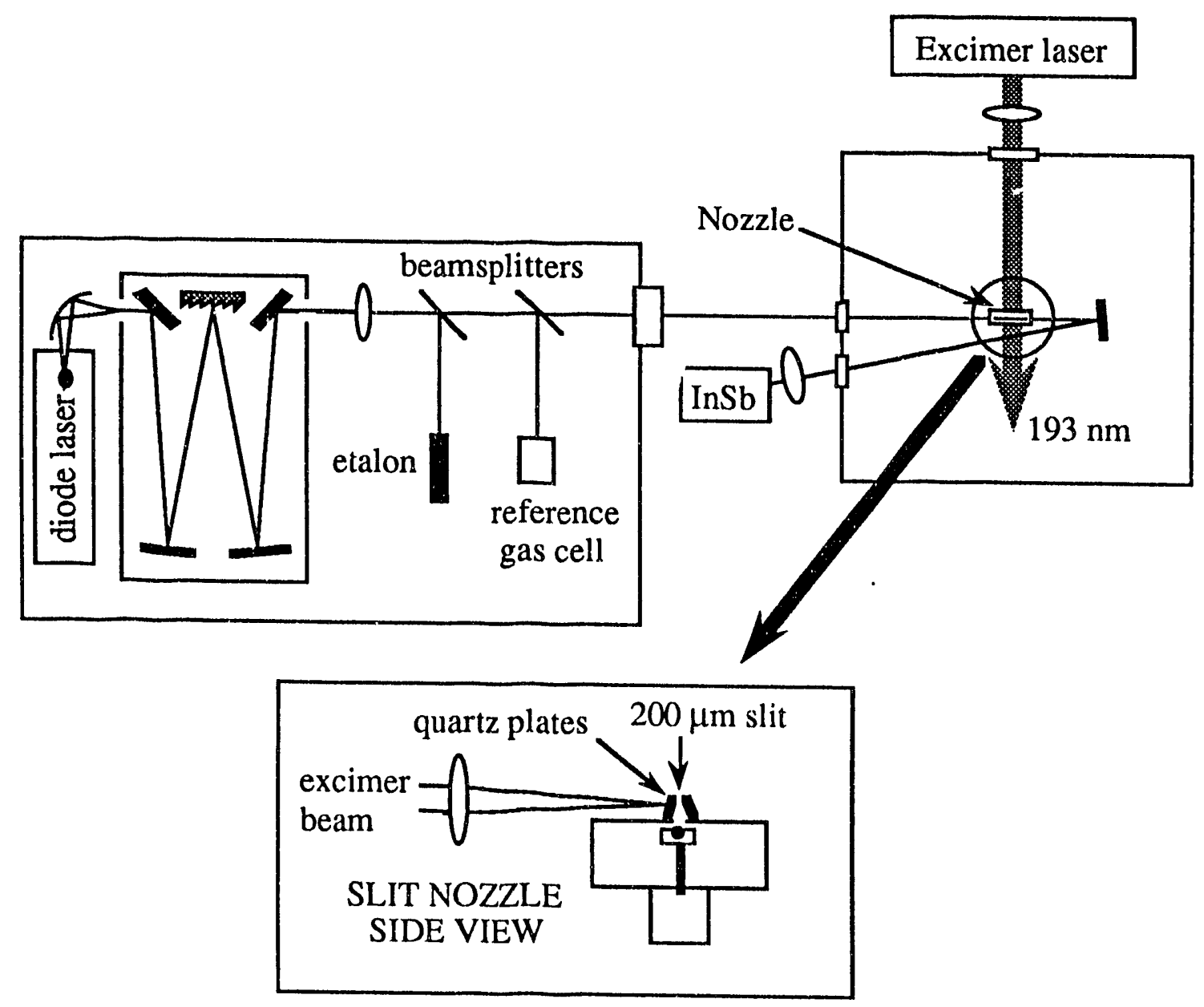

Fig. 3. Experimental setup for preparing transient species. The diode laser system is on antical table and the excimer laser is in a screen room.

C. Tunable diode lasers and the optical system

Our present systems are both based on Spectra Physics (Laser Analytics) TDL technology; each system is equipped with a cold-head that holds four diories, and uses a $0.5 \mathrm{~m}$ monochromator to separate laser modes. Presently, diodes cover the region 350 $2650 \mathrm{~cm}^{-1}$, but a given diode is guaranteed for a range of only $15 \mathrm{~cm}^{-1}$, but usually covers $\sim 150 \mathrm{~cm}^{-1}$. However, recent improvements in device fabrication, especially using molecular beam epitaxy (MBE), provide dramatically improved devices, and the manufacturer keeps promising to extend the high frequency limit to $3000 \mathrm{~cm}^{-1}$ in the near future. 
The inherent laser linewidth is $8 \mathrm{MHz}\left(0.0002 \mathrm{~cm}^{-1}\right)$. However, microphonics and electronic instabilities create frequency jitter, making effective linewidths $\sim 30 \mathrm{MHz}$. Since the resonance linewidths in our experiments are Doppler limited at $\sim 90 \mathrm{MHz}$, this is not overly restrictive. However, the gas flow in slit expansions is laminar in the center of the jet, with molecules traveling parallel to each other. Only m jlecules at the edge of this ribbon expand sideways from the jet and contribute to the Doppler width. Thus, we can reduce the Doppler widths without changing the maximum absorption intensity by skimming the edges of the gas ribbon. We have not seen the need to do this yet.

The laser beam is split into three parts, as shown in Fig. 4. The main beam passes through the expansion 6-10 times, and the other beams pass through an etalon and a reference gas cell. Each has its own detector and data acquisition system because data from all three channels must be obtained simultaneously. Frequency measurements are made with a $7.5 \mathrm{~cm}$ Ge etalon, temperature-stabilized to better than $\pm 0.01 \mathrm{~K}$. This etalon is very susceptible to minute temperature changes as well as the phase of the moon. A reference gas determines the absolute frequency and is used to calibrate the eta ${ }^{\prime} \mathrm{on}$ spacing for each run. The frequency stability of the system is dependent on the particular diode in use, but is capable theoretically of $\pm 8 \mathrm{MHz}$. Measurements have been greatly improved with the addition of an air-spaced etalon that can be used either as a passive etalon or one to which the laser can be locked and scanned by changing the length of the cavity. The air spaced etalon can be used with either system. Noise in the laser frequency/intensity originates from the microphonics associated with the closed cycle refrigerator that cools the diodes to liquid helium temperatures. Diodes are now available that operate above 77 $\mathrm{K}\left(\mathrm{LN}_{2}\right)$. Then the cooler can be replaced with a dewar. Experience of other users has shown that this can reduce the noise by an order of magnitude. We propose to purchase such dewars for both setups with USC cost sharing funds. The diodes for these dewars are hand selected. Thus, they are the best diodes that can be cbtained. The remaining diodes are sold for the older refrigerated systems.

We and most other users are not happy with the main American supplier, Laser Analytics. The improvements in diode characteristics that we anticipated have not occurred. However, a German company, Mutek now has a US distributor, so these diodes can te purchased without the annoyance of obtaining import licenses. We have purchased two of these diodes and found them to be of better quality than Laser Analytics'. However, thay are more expensive. 


\section{Data acquisition.}

Data are obtained in what we refer to as slow and fast-scan modes. In the slow scan mode, a series combination of lock-in amplifier and transient digitizer are used, as shown in Fig. 4. The laser frequency is dithered at $10 \mathrm{kHz}$ to shift data acquisition to a low noise portion of the spectrum. After the $20 \mathrm{kHz}$ signal component is averaged and the background subtracted, it is sent to the AT computer for processing. Signals from the etalon, reference gas cell, and nozzle expansion are obtained simultaneously to prevent errors due to drift. This approach provides beautiful spectra with flat baselines.

More recently, we developed a fast scan method that uses three digitizers to simultaneously record spectra of the reference gas, the etalon and the complex. This provides the spectrum of a single gas pulse of $1 \mathrm{~ms}$ duration over at least $1 \mathrm{~cm}^{-1}$ at $0.003 \mathrm{~cm}^{-}$ ${ }^{1}$ resolution! This spectrum can be further improved by averaging multiple pulses without significant drift. Thus, a complete spectrum over a few $\mathrm{cm}^{-1}$ can be taken in a few minutes. Since this :ime duration is short, drifts of the etalon and laser are not harmful. 1.

Both of these methods have their advantages and unique uses. The fast scan mode will be very attrar+ive as a diagnostic technique in molecular dynamics experiments. Absorptions are typically about $10 \%$ for these clusters after 1-3 shots per point.

The electronic acquisition system described above is not suitable for species produced by photolysis since the laser burns a spatial hole in the gas pulse. Data acquisition is controlled by a computer and a 12-bit transient digitizer is used to monitor absorptions. Both etalon and reference signals are chopped and detected using lock-in amplifiers whose outputs are monitored by a 16-channel A/D converter. Triggering is such that the valve opens during a quiet period of the compressor cycle, and the excimer laser is fired after an expansion has formed. A few $\mu$ s later, the digitizer and oscilloscope are triggered. The digitizer samples the waveform prior to and after the trigger, and the computer integrates both waveforms and subtracts the pre-trigger value from the post-trigger one, thus canceling the baseline. Immediately after the absorption signal is digitized, the A/D converter is initiated to read both the etalon and reference signals. At the same time, the diode laser is slowly scanned by using the internal sweep generator of the laser control module. The computer is also interfaced to a stepping motor, which adjusts the monochromator setting to allow maximum transmission of the selected laser mode. 


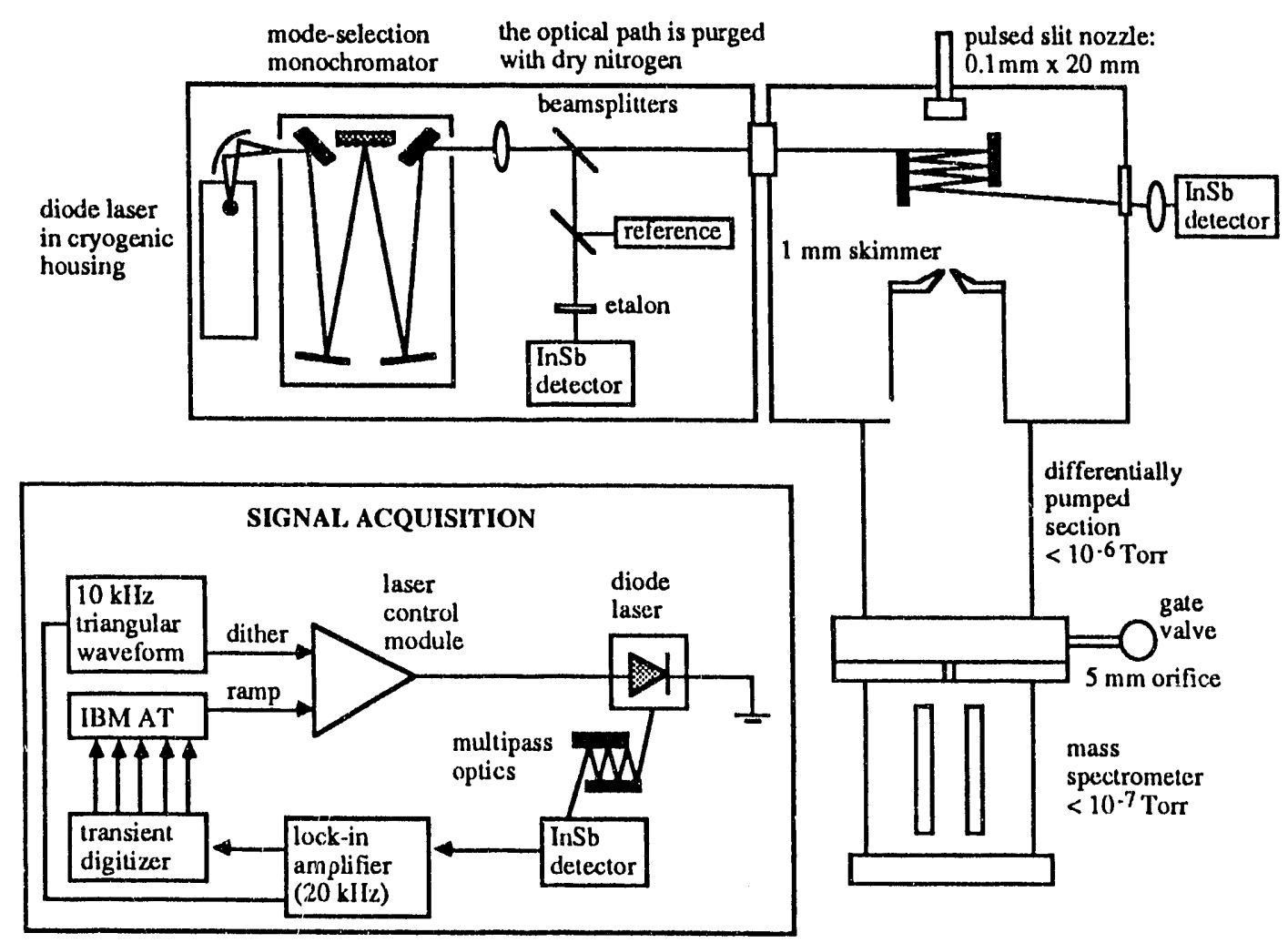

Fig. 4. Experimental apparctus

\section{BINARY COMPLEXES CONTAINING OXYGEN ATOMS.}

For the last year and a half, our greatest effort has been direcred at finding complexes of $\mathrm{O}\left({ }^{3} \mathrm{P}\right)$ with small molecules of interest in combustion. This was the most ambitious, but risky, segment of the work proposed originally. However, because it had the highest payoff, it received our concentrated effort. Our goal was to produce $\mathrm{O}\left({ }^{3} \mathrm{P}\right)-\mathrm{HX}$ complexes and to study reactions induced by essentially vibrational excitation. Our first approach for producing atomic oxygen was the photolysis of $\mathrm{NO}_{2}$ at $390 \mathrm{~nm}$. We chose this because the oxygen atoms are known to be translationally cold, a necessary condition so that atoms do not escape from the beam before clustering. 5 Unfortunately the quantum yield was low, and the $\mathrm{NO}_{2}$ reacted with most substituents that were added to the gas mixture prior to photolysis. We then proceeded to photolyze $\mathrm{SO}_{2}$ to produce atomic oxygen. As mentioned above, this works. Satisfactory results have been obtained for the generation of $\mathrm{O}\left({ }^{3} \mathrm{P}\right)$ by photolysis of $\mathrm{SO}_{2}$ at $193 \mathrm{~nm}$ with a Lambda Physik EGM 201 excimer laser.

$$
\left.\mathrm{SO}_{2} \longrightarrow \mathrm{SO}^{3} \mathrm{\Sigma}^{-}\right)+\mathrm{O}\left({ }^{3} \mathrm{P}\right)+6300 \mathrm{~cm}^{-1}
$$


Because the $O\left({ }^{3} \mathrm{P}\right)$ cannot be directly observed with our current experimental setup, we have inferred the production of the ground state oxygen atoms by detecting the vibrational spectrum of the co-produced transient species, $\left.\operatorname{SO}^{3} \Sigma^{-}\right)$. This is justified in view of the previous kinetics studies of this process". From the rate constants obtained in these studies, we conclude that the most efficient process for $\mathrm{O}\left({ }^{3} \mathrm{P}\right)$ removal is the recombination to form $\mathrm{SO}_{2}$ and, as a result, the concentration of $\mathrm{O}\left({ }^{3} \mathrm{P}\right)$ and $\left.\mathrm{SO}^{3} \mathrm{\Sigma}^{-}\right)$are approximately the same under our experimental conditions.

Since the vibrational fundamental of SO at $1138 \mathrm{~cm}^{-1}$ is outside the range of our IR optics, we studied the much weaker $v=0 \rightarrow 2$ overtone transitions at $2263 \mathrm{~cm}^{-1}$.

Despite the fact that the radicals were cooled down to only $T_{R}=70 \mathrm{~K}$, about $0.8 \%$ absorption of the IR laser power was ow red for some of the strong transitions. This indicates that a significant amount of $\mathrm{SO}\left({ }^{3} \mathrm{Z}^{\prime-}\right)$, and hence $\mathrm{O}\left({ }^{3} \mathrm{P}\right)$, was generated and survived in the free jet expansion. Because the overtone spectra of $\left.\operatorname{SO}^{3} \Sigma^{-}\right)$had not been measured previously, we recorded the rovibrational spectrum of SO and are in the process of analyzing it for publication. Though the absorption cross-section for the overtone is low, we obtained strong absorption signals. We estimate that essentially all the $\mathrm{SO}_{2}$ in the photolysis region is decomposed.

We have attempted to cluster the oxygen with a large number of constituents, including $\mathrm{CO}_{2}, \mathrm{CO}$ and $\mathrm{N}_{2} \mathrm{O}$, all of which have excellent IR absorption cross-sections. The temperature of the expanded gas is estimated from relative intensities of rotational lines of $\mathrm{SO}$ or of $\mathrm{CO}_{2}$ that has been added to the mixture. In both cases, $\mathrm{T}_{\mathrm{R}} \sim 70 \mathrm{~K}$. At high temperatures, there is not much likelihood that clusters will be produced. $T_{R}$ can be lowered by reducing the concentration of $\mathrm{SO}_{2}$ with the consequent reduction of the $\mathrm{SO}$ and $\mathrm{O}\left({ }^{3} \mathrm{P}\right)$ concentrations. This work has been described in a manuscript. ${ }^{6}$ A portion of the SO overtone spectrum is shown in Fig. 5. Though absorption cross-sections are low, the $\mathrm{S} / \mathrm{N}$ is high. If clusters are present, we have not been able to detect them. We will make one last attempt to make a radical-molecule cluster observable by IR absorption. Dr. Yaomin Lin who obtained his Ph.D. with M. Heaven is attempting to produce and detect Ar-OD. We are awaiting a diode in the $2360 \mathrm{~cm}^{-1}$ region for this experiment. If successful we can bootstrap up from there. If not, this experiment will be discontinued. 


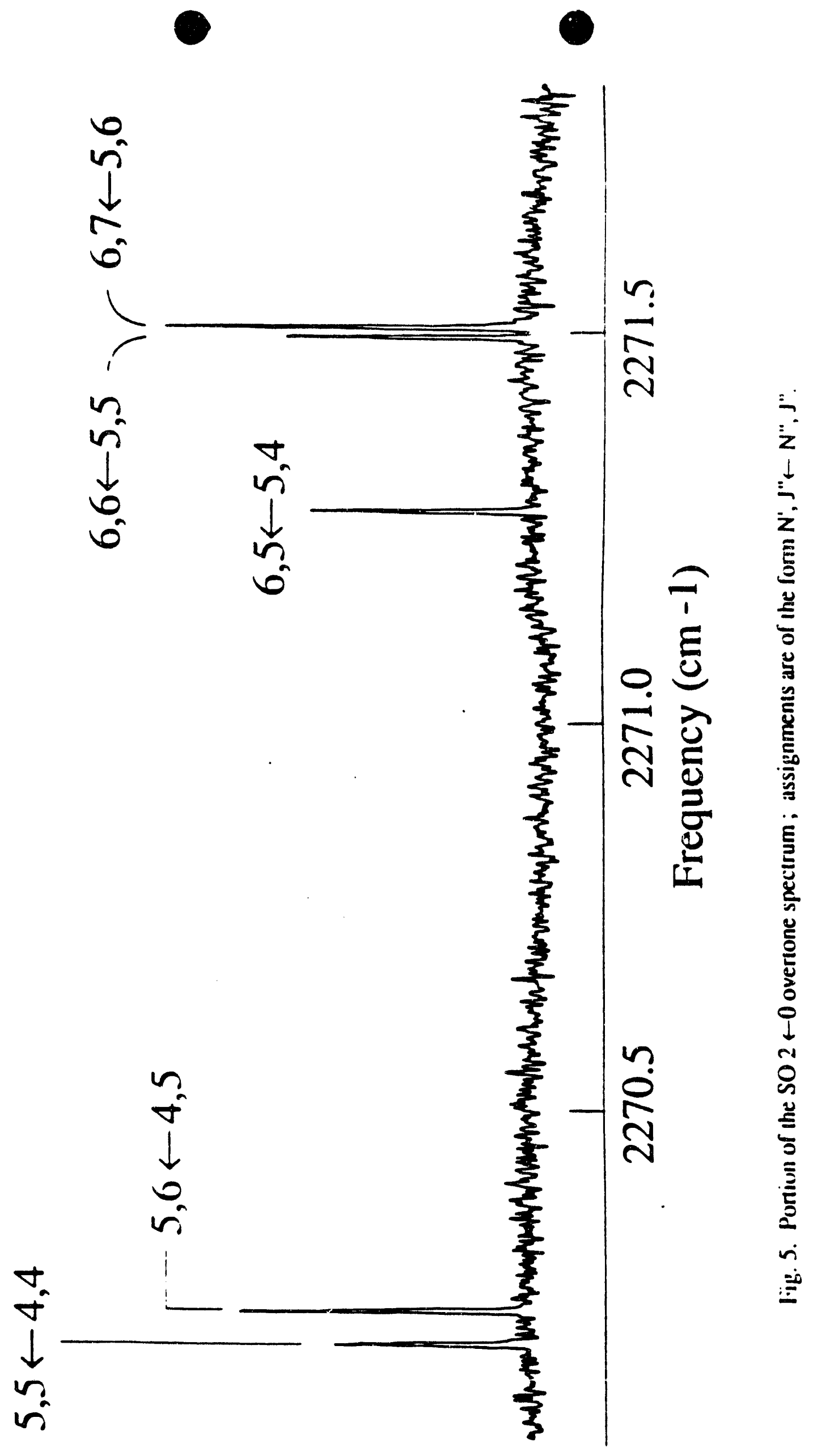




\section{BINARY COMPLEXES CONTAINING O2.}

There has been almost no experimental work on complexes containing $\mathrm{O}_{2}$, i.e., a single report in the Soviet literature on $\mathrm{Ar}-\mathrm{O}_{2},{ }^{7}$ absorption spectra in a long multipass cell, ${ }^{8}$ and its magnetic spectrum was also observed. ${ }^{9}$ Of course, there is a reason for this: because the ground electronic state of $\mathrm{O}_{2}$ is $3 \Sigma$, spectra are complicated, and it has proveri difficult to form complexes. On the other hand, the $\mathrm{O}_{2}$ spectrum is well understood The rotational spectrum has been studied via magnetic-dipole-allowed transitions, ${ }^{10}$ and the Hamiltonian is usually best expressed in a Hund's case (b) representation. Beside rotational energy, two other terms are required to explain the level spacings: the $\gamma \mathrm{S} \cdot \mathrm{N}$ term, which is an interaction between the magnetic dipole due to the electron spin and molecular rotation, and $\lambda \mathbf{S} \cdot \mathbf{L}$, a magnetic polarization of the electronic angular momentum that mixes in some $\Pi$ character. The associated constants are $B_{0}=43,101$ $\mathrm{MHz}, \lambda=59,501 \mathrm{MHz}$ and $\gamma=252.7 \mathrm{MHz} .{ }^{11}$ The theory of the spectroscopy of $\mathrm{O}_{2}$ complexes has been discussed only once in the literature ${ }^{12}-a b$ initio calculations suggest that $\lambda$ and $\gamma$ may be strongly perturbed by the anisotropy of the clustering partner and that the spin quantization axis is rotated from the axis of symmetry. ${ }^{13}$

We have tried to form these complexes by expanding $\mathrm{O}_{2}$ /hydride mixtures in argon and in neon without much success. By varying the backing pressure and the composition of the expanding gas, cooling can be controlled over a limited range, e.g., increasing the backing pressure lowers the temperature, thereby increasing condensation. We were unsuccessful with $\mathrm{O}_{2}$ as the carrier gas; it was not an effective coolant and it seemed to promote the formation of dimers such as $\left(\mathrm{N}_{2} \mathrm{O}\right)_{2}$ and $(\mathrm{HCl})_{2}$. These experiments were tried wirh a $4 \mathrm{~cm}$ pulsed slit, and the results were marginal and not reproducible. Also, we could not use helium as a carrier gas except at low stagnation pressures. It was not until we sought oxygen complexes in the new apparatus with its $12 \mathrm{~cm}$ slit and high pumping throughput that we were successful. The key to success was "sing helium as a carrier, with backing pressures $\sim 2$ atm, high pumping speeds and good vacuum. Low temperatures were achieved without the competition of an efficient clustering gas such as argon. In fact, this is an excellent way to form high yields of these dimers without contaminants. We hypothesize that because argon and neon are good clustering agents, they preferentially complex with, and deplete, other reagents. Helium does not cluster so well, but requires high pumping speeds to remove it from the chamber efficiently and achieve the low temperatures. Our best results are obtained with $\mathrm{N}_{2} \mathrm{O} / \mathrm{O}_{2} / \mathrm{He}$ mixtures of 1/10/1500 and stagnation pressures of about 2 atmospheres. 

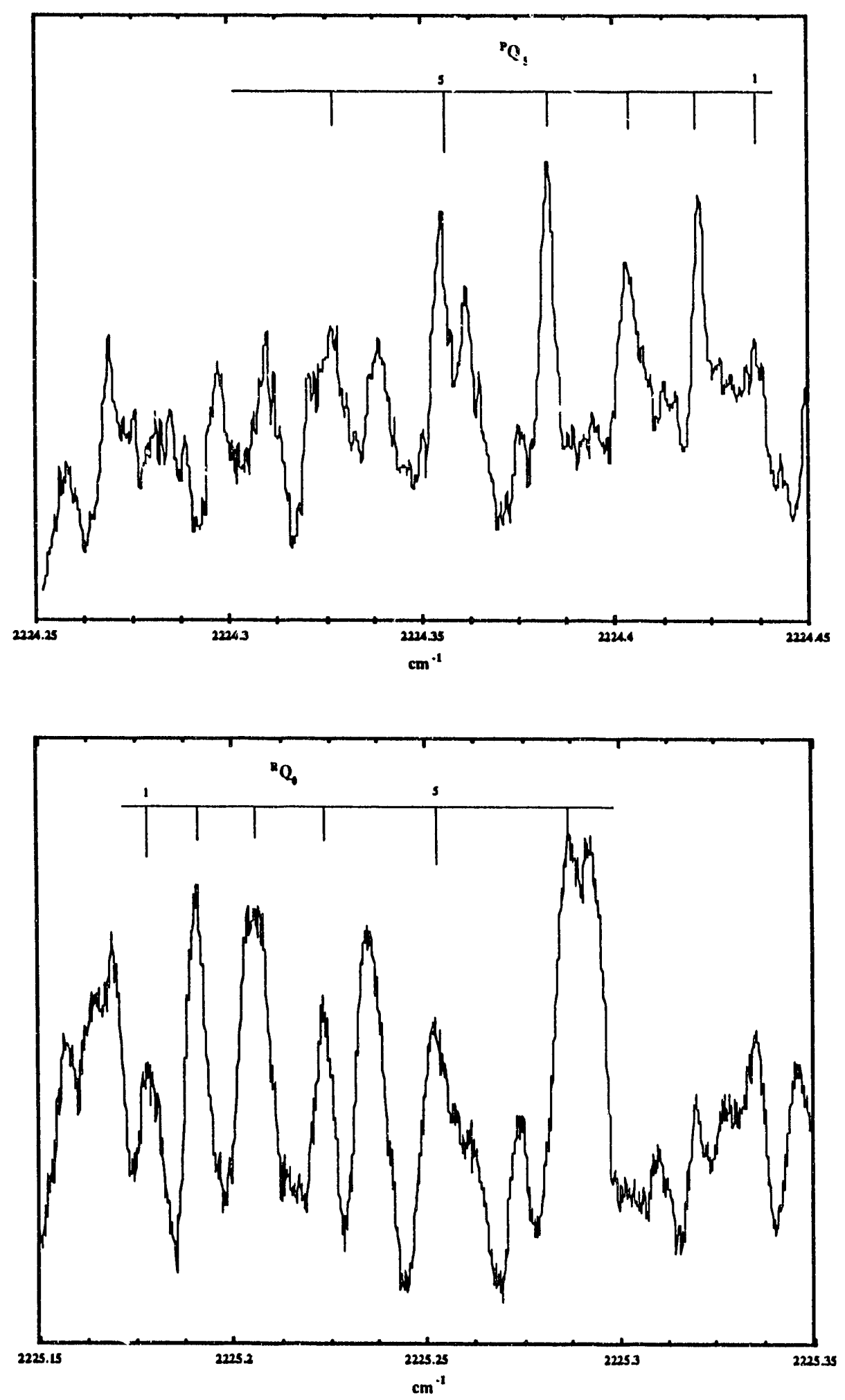

Fig. 6. Portion of $\mathrm{N}_{2} \mathrm{O}-\mathrm{O}_{2}$ spectrum with assignment of progressions. 
Figure 6 shows portions of an $\mathrm{O}_{2}-\mathrm{N}_{2} \mathrm{O}$ spectrum. A full spectrum spans $\sim 4 \mathrm{~cm}^{-1}$, and we have also seen lines that appear to originate from $\mathrm{He}-\mathrm{N}_{2} \mathrm{O}$, which has not been seen before. $\mathrm{CH}_{4}-\mathrm{N}_{2} \mathrm{O}$ spectra have also been taken, and though not yet completely assigned, definite progressions have been identified. We have also collected an arsenal of computational tools for assignments and fitting. From JPL, we have two computer programs that handle asymmetric rotors with three other spins, including electronic spin, as variables. One program predicts energies, frequencies, and intensities, while the second performs a least square fitting of the data to determino constants. ${ }^{14}$ Also, we acquired a Loomis-Woods assignment program that assists in finding line progressions and assignments ${ }^{15}$ We must reiterate that this is the first molecule with two unpaired spins to be studied. Thus, we now know how to generate binary clusters containing $\mathrm{O}_{2}$. This expertise should be applicable to oxygen-hydride complexes.

\section{THE MOLECULAR STRUCTURE OF $\mathrm{CO}_{2}$-HX BINARY COM- PLEXES}

Binary van der Waals comlexes have found use in molecular dynamics as a method of prealigning two molecules prior to photoinitiating a chemical reaction. ${ }^{16}$ This technique was first demonstrated by Wittig and his coworkers with the reaction of $\mathrm{H}+$ $\mathrm{CO}_{2} \rightarrow \mathrm{CO}+\mathrm{OH}$. The complex $\mathrm{CO}_{2}-\mathrm{HBr}$ and $\mathrm{CO}_{2}-\mathrm{HCl}$ were first formed in a free jet expansion and then photolyzed at $193 \mathrm{~nm}$ with an excimer laser. ${ }^{17}$ The structure of the complex determines the entrance channel geometry. The product state distributions were probed with LIF.

In this approach of studying photoinitiated chemical reaction dynamics, information about the structure of the complex is essential for understanding the effect of entrance channel parameters on reaction probabilities, branching ratios, product state distributions, and reaction times. In order to obtain the structural information for $\mathrm{CO}_{2}-\mathrm{HX}$ complexes $(\mathrm{X}=\mathrm{F}, \mathrm{Cl}$ and $\mathrm{Br})$, we have employed infrared spectroscopic techniques to observe the rovibronic spectrum of complexes by exciting the $\mathrm{CO}_{2}$ asymmetric stretch ( $v_{3}$ mode) chromophore. ${ }^{18}$ The structures of $\mathrm{CO}_{2}-\mathrm{H}(\mathrm{D}) \mathrm{F}$ and $\mathrm{CO}_{2}-\mathrm{H}(\mathrm{D}) \mathrm{Cl}$ were found to be quasi-linear (i.e., hinge-like with broad zero-point amplitudes) for both the ground and the first vibrationally excited states. The ground-state rotational constants were in excellent agreement with both the microwave spectroscopic studies of $\mathrm{CO}_{2}-\mathrm{H}(\mathrm{D}) \mathrm{F}^{19}$ and $\mathrm{CO}_{2}$ - 
$\mathrm{H}(\mathrm{D}) \mathrm{Cl}^{20}$ and other infrared spectroscopic results for $\mathrm{CO}_{2}$ - $\mathrm{HF}$, where the HF chromophore was excited. ${ }^{21}$ However, the $\mathrm{CO}_{2}-\mathrm{HBr}$ rovibrational spectrum showed the typical $b$-type spectrum of an asymmetric rotor, a pattern dramatically different from linear molecules such as $\mathrm{CO}_{2}-\mathrm{HF}$ and $\mathrm{CO}_{2}-\mathrm{HCl}$. Analysis of this spectrum indicated that the structure of $\mathrm{CO}_{2}-\mathrm{HBr}$ is $\mathrm{T}$-shaped with the $\mathrm{C}$ - $\mathrm{Br}$ interatomic distance almost perpendicular to the $\mathrm{CO}_{2}$ molecular axis, which is similar to $\mathrm{CO}_{2}-\mathrm{Ar}^{22}$ if we ignore the hydrogen atom. The structural variation in going from $\mathrm{CO}_{2}-\mathrm{HF}(\mathrm{HCl})$ to $\mathrm{CO}_{2}-\mathrm{HBr}$ was ascribed to a competition between hydrogen-bonding favoring a linear geometry and dispersive forces favoring the $\mathrm{T}$-shape. Besides, the shift in frequency, relative to uncomplexed $\mathrm{CO}_{2}$, of the $\mathrm{CO}_{2}$ asymmetric stretch band origin appeared to correlate with the structural change, i.e, a blue shift for linear $\mathrm{CO}_{2}-\mathrm{H}(\mathrm{D}) \mathrm{F}(\mathrm{Cl})$ and a small red shift for the T-shaped $\mathrm{CO}_{2}-\mathrm{HBr}$. However, the position of the $\mathrm{H}$ atom in the $\mathrm{CO}_{2}-\mathrm{HBr}$ complex was not determined. The location of the hydrogcn is obviously key to understanding the photoinitiated reaction dynamics. Subsequently, by comparing the nuclear quadrupole coupling constant of the bromine atom in the complex and the free $\mathrm{HBr}$, Rice $e t$ al. have determined that "the hydrogen is positioned at an angle of $\sim 66^{\circ}\left(114^{\circ}\right)$ from the $a$-axis of the complex." 23

As a further effort to determine unequivocably the structural features of the $\mathrm{CO}_{2}$ $\mathrm{HBr}$ complex, we have now obtained the $\mathrm{CO}_{2}-\mathrm{DBr}$ infrared rovibrational spectrum to complement our previous studies on $\mathrm{CO}_{2}-\mathrm{HBr}^{24}$ The position of the $\mathrm{H}(\mathrm{D})$ atom is determined from the difference between the $\mathrm{CO}_{2}-\mathrm{DBr}$ and $\mathrm{CO}_{2}-\mathrm{HBr}$ moments-of-inertia. The $\mathrm{H}$ atom lies in the $\mathrm{Br}-\mathrm{CO}_{2}$ plane, and on average almost parallel to the $\mathrm{CO}_{2}$ molecular axis. (Cf. Fig.7.) The structure is best described as an inertially T-shaped, slipped-parallel geometry, analogous to that of the $\mathrm{CO}_{2}$ dimer. ${ }^{25}$ These results are in some disagreement with Rice's result of $66^{\circ}$ or $114^{\circ}$ for $\theta_{\mathrm{HBrC}}$.

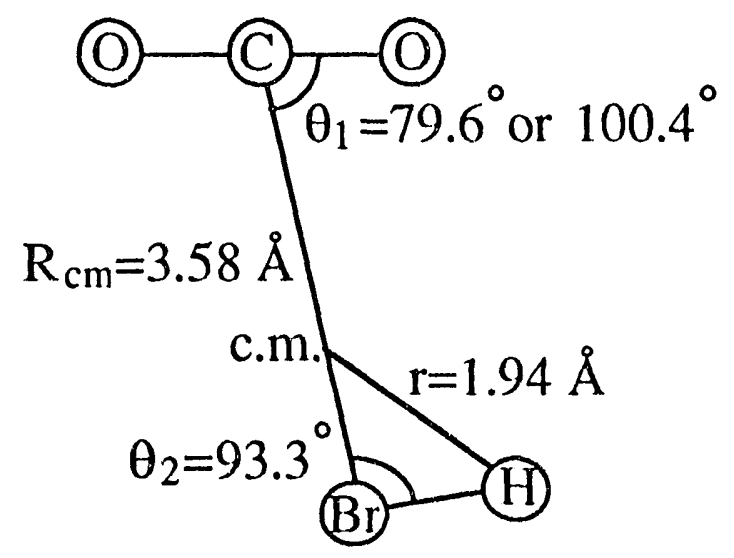

Fig. 7. Experimentally determined structure of $\mathrm{CO}_{2}-\mathrm{HBr}$. 


\section{THE RELIABILITY OF STRUCTURES DETERMINED BY SPEC'TROSCOPIC METHODS.}

However, this approach for locating atoms used in rigid molecules may not be appropriate if the molecule is too floppy. Thus it is important to determine the floppiness of the complex. So, to provide a better understanding of the anisotropic force field binding the $\mathrm{CO}_{2}-\mathrm{HBr}$ complex, to determine equilibrium geometries of the ground state complex, and to estimate the floppiness about this equilibrium structure, we have carried out $a b$ initio computations by using Møller-Plesset second-order perturbation (MP2) methods ${ }^{26}$ with double-zeta plus double polarization basis sets. The results of the calculations are in close accord with the experimental results. They substantiate a geometry with the $\mathrm{Br}-\mathrm{H}$ bond essentially parallel to the $\mathrm{O}-\mathrm{C}-\mathrm{O}$ axis. The computed structure is given in Fig. 8.

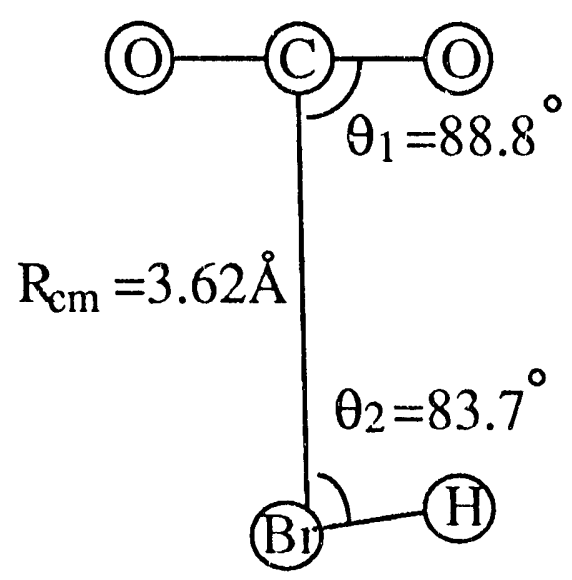

Fig. 8. Structure derived from ab initio computations.

Though these computations are lengthy, we have determined portions of the potential energy surface about the equilibrium point with respect to rotation of the $\mathrm{HBr}$ both in and out of the plane of the complex. This PES has been determined for the rotation of the $\mathrm{HBr}$ about its center of mass (1) at a constant $R_{c m}$ and (2) at values of $R_{c m}$ at which the energy is a minimum, for each orientation of the HBr. Fig. 9 illustrates the PES for calculations at constant $R_{c m}=3.62 \AA$. Fig. 10. plots the value of $R_{c m}$ at the minimum energy for each angle $\theta_{\mathrm{HBrC}}$. The values of the energy along this minimum potential energy valley is given in the Fig. 11. These results form an upper bound to the heights of the potential barriers for these degrees of freedom. The barrier height for the out of plane rotation of the $\mathrm{HBr}$ agrees fortuitously close to the experimentally determined value and confirms that the explanation for the discrepancy between our observed A constant and that in the microwave is due to this interaction. Then, we have determined the energy 


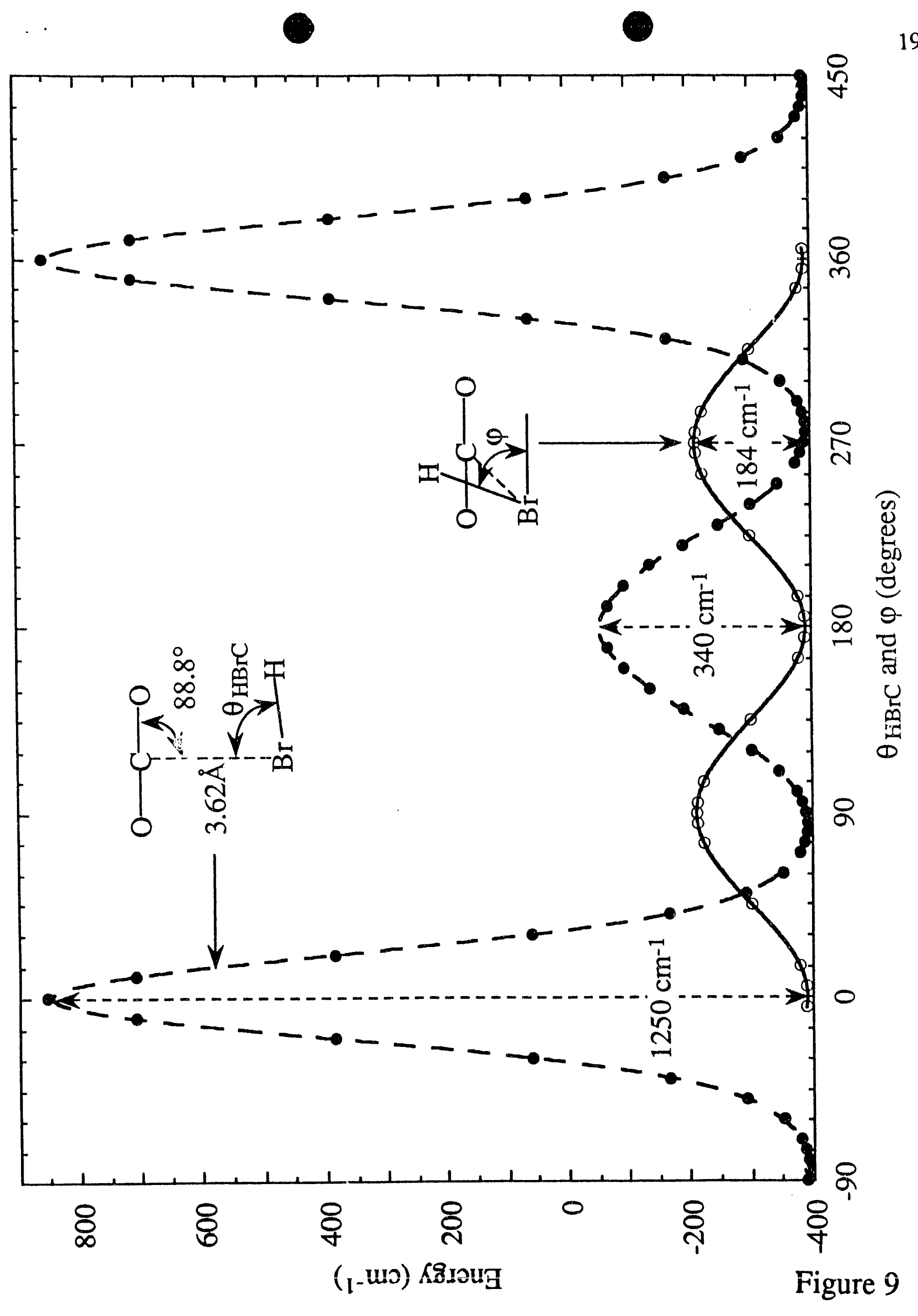




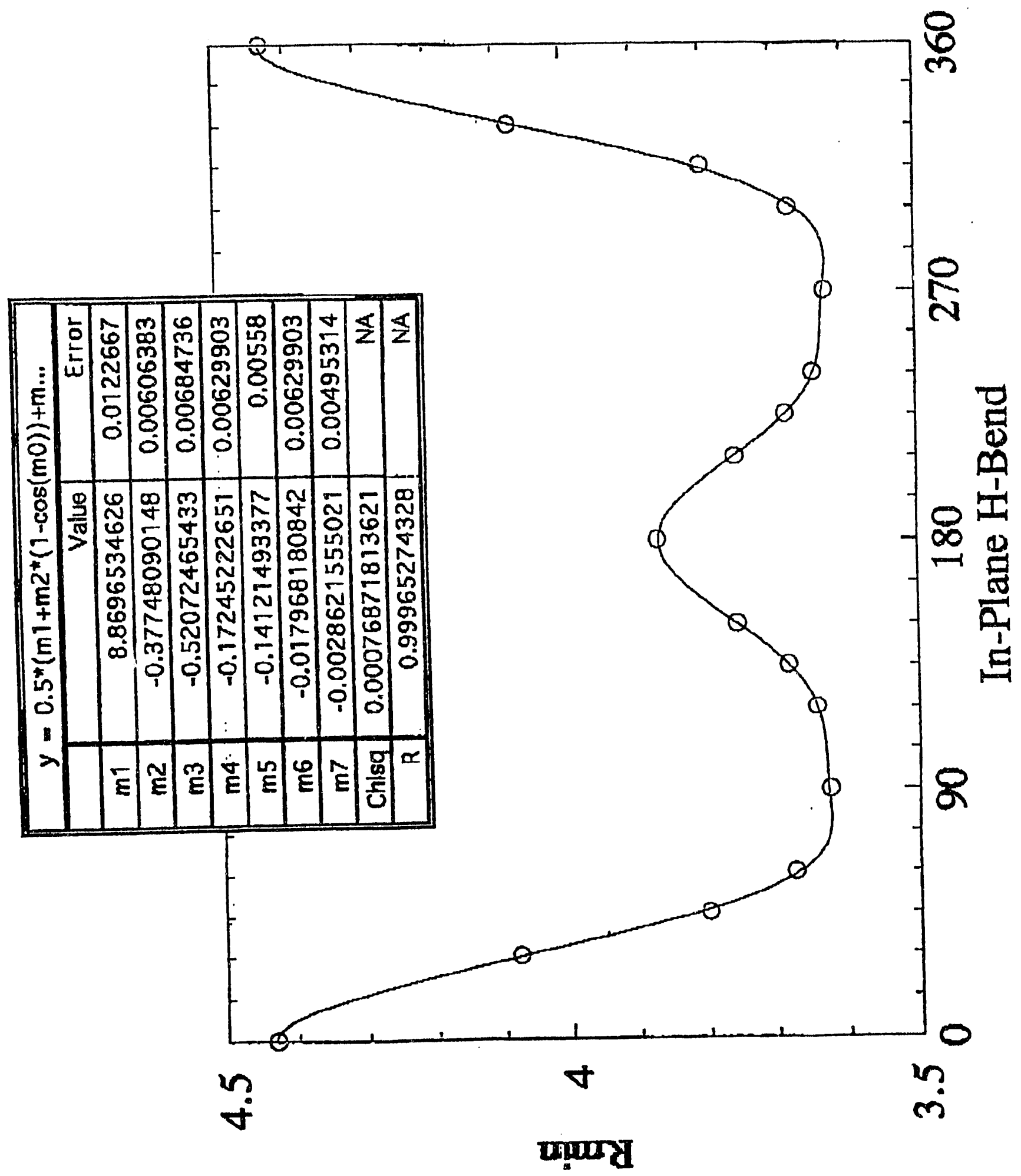

Figure 10 


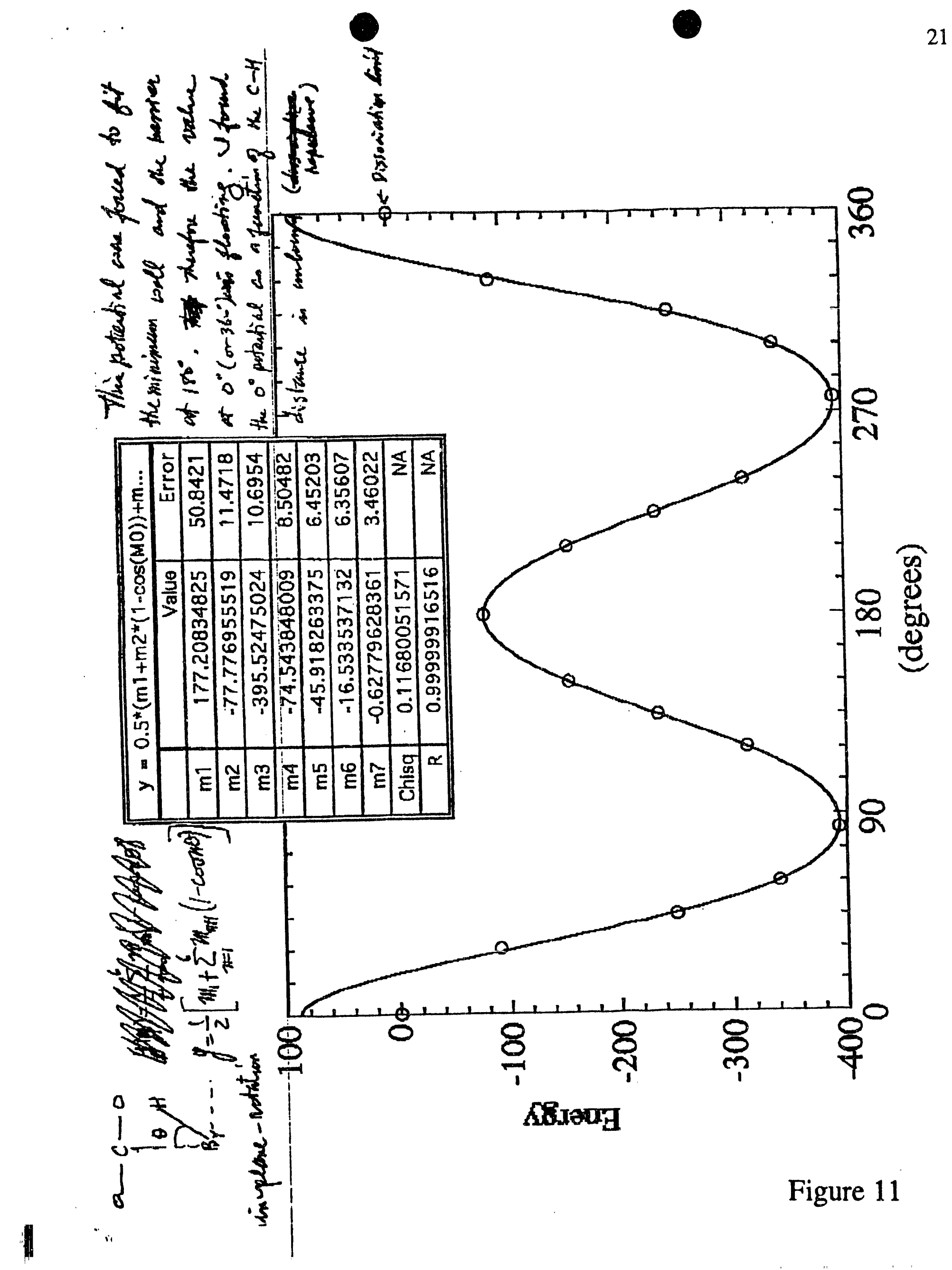


levels, eigenfunctions, expectation values and dispersions of the angle for the $\mathrm{H}(\mathrm{D}) \mathrm{Br}$ rotation in the plane.

For these last calculations, we have used a computer program, ASTORT, developed by Groner and Durig that solves the one dimensional Hamiltonian for a cyclic potential,

$$
\left[F(\theta) P_{\theta}^{2}+V(\theta)=E_{V}\right] \psi(\theta)
$$

where $\theta$ is the internal rotation variable, $F(\theta)$ represents the angle dependent reduced moment of inertia of the complex (the $\mathrm{G}$ matrix element), expressed as a truncated 16term Fourier series, $V(\theta)$ is the potential energy expressed as a six term Fourier series,

$$
\mathrm{V}(\theta)=(1 / 2) \sum_{n} V_{n}(1-\cos n \theta)
$$

$\mathrm{F}(\theta)$ takes into account the changes in structural parameters as the asymmetric internal rotor angle, $\theta$, reorients itself. The Hamiltonian is diagonalized in a truncated free rotor basis set where sufficient terms are retained to converge the lower energy levels. The vibrational energy levels and wavefunctions in the two internal rotation potentials have been calculated. The program was modified to calculate the expectation values of $\theta, \theta^{2}$, and the dispersion in $\theta$.

These calculations indicate no tunneling with in-plane motions and only small differences between the $H$ and $D$ zero point effects. Thus the molecule appears to be semirigid, with a propensity for large-amplitude $\mathrm{H}$-atom zero-point excursions, which accommodate significant reactivity when the HX moiety is photoexcited with a UV photon. The reason that structures are valid, at least in this case can be attributed to the strong coupling between the stretch of the $R_{\mathrm{cm}}$ and the in plane bend of the $\mathrm{HBr}$ about its center of mass: the reduced mass for this motion involves not only the mass of the hydrogen(or deuterium) but also of the bromine. As the hydrogen moves away from its equilibrium position the bromine also must move away from the $\mathrm{CO}_{2}$ moiety. There is no simple tunneling motion of a light hydrogen atom in this case. Thus, these molecules can be treated with rigid or semirigid hamiltonian used for stable molecules. The final conclusion is that the structures determined for the $\mathrm{CO}_{2}-\mathrm{HX}$ (and the $\mathrm{N}_{2} \mathrm{O}-\mathrm{HX}$ ) are meaningful though the amplitudes of the vibrations are perhaps an order of magnitude larger than tin those cases. 
Thus we recommend that such an analysis is useful in many cases to evaluate the validity of any structure determination for these flexible van der Waals complexes. We still have no explanation for the large discrepancy between our results obtained with isotopic substitution and those of Rice et al. obtained by using the nuclear quadrupole coupling results. ${ }^{23}$ It's possible that complexation of these large easily polarizable atoms have more effect on the nuclear quadrupole field than has been anticipated. Expecting that the environment is the same as in the free monomer, in this case $\mathrm{HBr}$, may not be such a great approximation after all.

\section{REFERENCES}

1 S. W. Sharpe, R. Sheeks, C. Wittig, and P A. Beaudet, Chem. Phys. Lett. 151, 267 (1988).

2. T. A. Miller, Science 223, 545 (1984).

3. D. E. Powers, J. B. Hopkins, and R. E. Smalley, J. Phys. Chem. 85, 2711 (1981).

4. S. Sharpe and P. Johnson, Chem. Phys. 107, 35 (1984).

5 Zacharias, H., Geilhaupt, M., Meier, K., and Welge, K. H. J. Chem. Phys. 74, 218 (1980).

6. Z. S. Huang, J. E. Verdasco, C. Wittig, and R. A. Beaudet, Chem. Phys. Lett. submitted.

7. V. A. Istomin, B. I. Zhilinskii, and N. F. Stepanov, Vetsn. Mosk Univ, Ser. 2: Khim. 20, 185 (1979)

8. G. Henderson and G. Ewing, J. Chem. Phys. 59, 2280 (1973)

9. J. Mettes, G. Heymen, P. Verhoeve, J. Reuss D. C. Laine and G. Brocks, Chem. Phys. 92, 9 (1985)

10. C. H. Townes, and A. L. Schawlow, Microwave Spectroscopy, McGraw-Hill, N. Y., 1955, p. $182 \mathrm{ff}$.

11. M. Mizushima and R. M. Hill, Phys. Rev. 93, 745 (1954),

12. J. Tennyson and J. Mettes, Chem. Phys. 76, 195 (1983).

13. Ad van der Avoird, J. Chem. Phys. 76, 1170 (1983).

14. H. M. Pickett, J. Molec. Spectr. 148, 371 (1991). 
15. B. P. Winnewisser, J. Reinstädtler, K. M. T. Yamada and $\therefore$ Behrend, J. Molec. Spectr. 136, 12 (1989).

16 (a) C. Wittig, S. Sh irpe and R.A. Beaudet, Acc. Chem. Res. 21, 341 (1988); (b) S.K. Shin, Y. Chem, S. Nickolaisen, S.W. Sharpe, R.A. Beaudet and C. Wittig, Advances in Photochemistry, V. 16, Eds. D. Volmar., G. Hammond and D. Neckers (Wiley, NY, 1991) pp. 249-363.

17 S.K. Shin, Y. Chen, D. Oh and C. Wittig, Phil. Trans. R. Soc. Lond. A 332, 361 (1990).

18 S.W. Sharpe, Y.P. Zeng, C. Witrig and R.A. Beaudet, J. Them. Phys. 92,943 (1990).

19 (a) F.A. Baiocchi, T.A. Dixon, C.H. Joyner and W. Klemperer, J. Chem. Phys. 74, 6544 (1981); (b) J.A. Shea, W.G. Read and E.J. Campbell, J. Chem. Phys. 79, 614 (1983).

20 R.S. Altman, M.D. Marshall and W. Klemperer, J. Chem. Phys. 77, 4344 (1982).

21 (a) C.M. Lovejoy, M.D. Schuder and D.J. Nesbitt, J. Chem. Phys. 86, 5337 (1987); (b) G.T. Fraser, A.S. Pine, R.D. Suenram, D.C. Dayton and R.E. Miller, J. Chem. Phys. 90, 1330 (1989).

22 R.W. Randall, M.A. Walsh and B.J. Howard, Faraday Discuss. Chem. Soc. 85, 1 (1988).

23 J.K. Rice, R.D. Suenram, F.J. Lovas, G.T. Fraser and W.J. Lafferty, Ohio State Symposium on Molecular Spectroscopy, 1990.

24 S.W. Sharpe, Y.P. Zeng, C. Wittig and R.A. Beaudet, J. Chem. Phys. 92, 943 (1990).

25 (a) M.A. Walsh, T.H. England, T.R. Dyke and B.J. Howard, Chem. Phys. Lett. 142, 265 (1987); (b) K.W. Jucks, Z.S. Huang, D. Dayton, R.E. Miller and W.J. Lafferty, J. Chem. Phys. 86, 4341 (1987).

26 Gaussian 90, Frisch, M. J.; Head-Gordon, M.; Trucks, G. W.; Foresman, J. B.; Schlegel, H. B.; Raghavachari, K.; Robb, M. A.; Binkley, J. S.; Gonzalez, C.; Defrees, D. J.; Fox, D. J.; Whiteside, R. A.; Seeger, R.; Melius, C. F.; Baker, J.; Martin, R. L.; Kahn, L. R.; Stewart, J. J. P.; Topiol, S.; Pople, J. A. Gaussian, Inc., Pittsburgh PA, 1990. 


\section{PUBLICATIONS SUPPORTED UNDER THIS DOE GRANT.}

57. Photoinitiated Reactions in Weakly-Bonded Complexes, C. Wittig, S. Sharpe, and R.A. Beaudet, Acc. Chem. Res. 21, 341 (1988).

62. Infrared Absorption Spectroscopy of $\mathbf{C O}_{2}$ - $\mathrm{HX}$ Complexes Using the $\mathrm{CO}_{2}$ Asymmetric Stretch Chromophore: $\mathrm{CO}_{2} \mathrm{HF}(\mathrm{DF})$ and $\mathrm{CO}_{2} \mathrm{HDI}(\mathrm{DCl})$ linear and $\mathrm{CO}_{2} \mathrm{HBr}$ Bent Equilibrium Geometries, S.W. Sharpe, Y.P. Zeng, C. Wittig, and R.A. Beaudet, J. Chem. Phys., 92, 943 (1990)

66. Photoinitiated Reactions in Weakly-Bonded Complexes, S.K. Shin, Y. Chen, S. Nicholaisen, S.W. Sharpe, R.A. Beaudet, and C. Wittig Adv. Fhotochem.. Vol. 15.

67. Photoinitiated Reactions in Weakly-Bonded Complexes: Entrance Channel Specificity, Y. Chen, Y.P. Zeng, S.K. Shin, G. Hoffmann, D. Oh, S. Sharpe, R.A. Beaudet, and C. Wittig, Submitted: Advance Molecular Vibrational and Collision Dynamics. Vol 1B, J. M. Bowman and M. A. Ratner, ed., 1991.

\section{SUBMITTED PAPERS}

1. Infrared Spectroscopy of $\mathrm{CO}_{2}-\mathrm{D}(\mathrm{H}) \mathrm{Br}$ and its molecular structure, Y. P. Zeng, S. W. Sharpe, S. K. Shin, C. Wittig, and R. A. Beaudet, submitted to Journal of Chemical Physics.

2. Infrared Absorption Spectroscopy of the Weakly Bonded $\mathrm{CO}-\mathrm{Cl}_{2} \mathrm{Complex}$. S. Bunte, J. B. Miller, Z. S. Huang, J. E. Verdasco, C. Wittig, and R. A. Beaudet. J. Phys. Chem.., accepted for publication.

3. High Resolution Infrared Diode Laser Spectroscopy of the $S\left({ }^{3} \sum^{-}\right)$in a Secondary-Slit Supersonic Expansion. Z. S. THang, J. E. Verdasco, C. Wittig, and R. A. Beaudet, Chem. Phys. Lett., accepted for publication.

4. Infrared Absorption Spectroscopy of the CO-Ar Complex, A. R. W. McKellar, Y. P. Zeng, S. W. Sharpe, C. Wittig, and R. A. Beaudet, J. Molec. Spectr., in press.

\section{ORAL PAPERS}

1. Photoinitiated Reaction of Atomic Hydrogen with $\mathrm{CO}_{2}$ : $\mathrm{OII}(\mathrm{v}=\mathbf{0})$

Rotational Distributions and HOCO Internal Energies From the $239 \mathbf{~ n m}$ Photolysis of $\mathrm{CO}_{2} \mathrm{HI}$ Complexes, 1989 Conference on the Dynamics of Molecular Collisions, July 126-21, Asilomar Conference Center, Pacific Grove, CA., July 16-21, 1989. 
2. Infrared Absorption Spectroscopy of Weakly-Bound van der Waals Complexes, 1989 Conference on the Dynamics of Molecular Collisions, July 1621, Asilomar Conference Center, Pacific Grove, CA., July 16-21, 1989.

3. Infrared Absorption Spectroscopy of Weakly Bound van der Waals Compls:xes, Amer. Chem. Soc. Meeting, Los Ängeles, September 25-30, 1988

4. Infrared Spectroscopy of the $\mathrm{CO}_{2}-\mathrm{D}(\mathrm{H}) \mathrm{Br}$ Complexes: Location of the Hydrogen Atom, $45^{\text {th }}$ Ohio State University Symposium on Molecular Specíroscopy, June 11-15, 1990.

5. The Rovibrational Spectrum, Structure and Intermolecular Dynamics of COAr, $45^{\text {th }}$ Ohio State University Symposium on Molecular Spectroscopy, June 11-15, 1990.

6. IR diode laser spectroscopy of radicals in supersonic expansions. Z. S. Huang, Curt Wittig, and R. A. Beaudet, XIII International Symposium on Molecular Beams, El Escorial, Madrid, Spain, 2-7 June, 1991.

7. High Resolution Infrared Diode Laser Spectroscopy of the $S O\left({ }^{3} \Sigma^{-}\right)$in a Secondary-Slit Supersonic Expansion., Z. S. Huang, J. E. Verdasco, C. Wittig, and R. A. Beaudet, HIRIS Meeting, Dijon, France, September, 1991.

To be presented this year at Columbus Ohio:

1. The reliability of structure determinations in large binary clusters: the case of $\mathrm{CO}_{2}-\mathrm{H}(\mathrm{D}) \mathrm{Br}$, S. K. Shin C. Wittig and R. A. Beaudet.

2. Infrared spectroscopy of the weakly bonded $\mathbf{C O}-\mathrm{Cl}_{2}$ Complex. S. W. Bunte, $\mathrm{Z}$. S. Huang, J. B. Miller, J. E. Verdasco, C. Wittig, and R. A. Beaudet.

3. Structure determination of the $\mathrm{N}_{2} \mathrm{O}-\mathrm{O}_{2}$ Binary Complex. S. W. Bunte, Y. Lin, and R. A. Beaudet.

4. Infrared spectroscopy of the weakly bonded $\mathrm{CH}_{4}-\mathrm{N}_{2} \mathrm{O}$ Complex. 
